\title{
Activation of Cadmium Under Simulated Solar Illumination and Its Impact on the Mobility of $\mathrm{Cd}$ in Flooded Soils
}

\section{Bihao Luo}

Hunan Agricultural University

\section{Chenfeng Xiao}

Hunan Agricultural University

\section{Yuling Liu}

Hunan Agricultural University

Li Li

Hunan Agricultural University

\section{Liang Peng}

Hunan Agricultural University

\section{Qingru Zeng}

Hunan Agricultural University

Si Luo ( $\nabla$ rose850101@163.com )

Hunan Agricultural University

\section{Research Article}

Keywords: Cadmium, CdS, Photodissolution, Stability, Soil

Posted Date: December 14th, 2021

DOI: https://doi.org/10.21203/rs.3.rs-1087534/v1

License: (c) (i) This work is licensed under a Creative Commons Attribution 4.0 International License.

Read Full License

Version of Record: A version of this preprint was published at Environmental Science and Pollution Research on March 8th, 2022. See the published version at https://doi.org/10.1007/s11356-022-19567-3. 


\section{Abstract}

In waterlogged paddy soils, cadmium (Cd) can be precipitated as cadmium sulfide (CdS) under reductive environment, thereby limiting the absorption of $\mathrm{Cd}$ by plants. Multiple environmental factors (such as water, $\mathrm{pH}$, Eh, etc.) played a role in the control of Cd mobility and bioavailability. In this study, we investigated the influence of the solar irradiation on the photo-dissolution of synthetic CdSmontmorillonite composites (CdS-M) in solution and the stability of Cdin natural soil. The release kinetic of $\mathrm{Cd}^{2+}$ showed that after the irradiation of simulated sunlight, CdS-M composites became less stable compared to the dark control. The solar irradiation seemed to enhance the release of $\mathrm{Cd}^{2+}$ from CdS significantly and continuously. Electron paramagnetic resonance (EPR) and quenching experiments confirmed that the photogenerated holes, $\mathrm{O}_{2}{ }^{-}$and $\cdot \mathrm{OH}$ were possibly involved in the photo-induced release of $\mathrm{Cd}^{2+}$, while the holes was primarily responsible for the reaction.

Irradiation under alkaline solution or the presence of $\mathrm{DOM}, \mathrm{PO}_{4}{ }^{3-}, \mathrm{CO}_{3}{ }^{2-}$ and urea markedly inhibited the photodissolution process of CdS. The photo-mediated activation of $\mathrm{Cd}$ was further confirmed in paddy soil under natural sunlight, with a nearly 3-fold increase in concentration of extractable Cd during the 15 days irradiation. This study highlights the importance of photochemical transformation of $\mathrm{Cd}$ in the environmental water and soil.

\section{Introduction}

Cadmium (Cd) is a non-essential biological element with high-potential toxicity, mobility and bioaccumulation. Anthropogenic activities, such as mineral exploitation, sewage irrigation, and fertilizer application have greatly increased Cd levels in the water and soil environment (Saini and Dhania, 2020). Among all the surveyed contaminants, $\mathrm{Cd}$ ranks first in the percentage of soil samples $(7.0 \%)$ exceeding the soil quality standards in China (Mahar et al., 2016). It is also one of the most harmful and widespread metals in agricultural soil of south China, which is readily absorbed by crop plants and threatens human health through the food chain (Wang et al., 2021).

When Cd enters the soil, it is first adsorbed on soil particles surface and then can be changed into other forms through various physicochemical or biological processes. In fact, the different forms of Cd often change with environmental conditions,auch as soil pH, Eh, DOM, CEC and organic matter content, etc., thus influencing its fate and bioavailability (Lu, 2000; Niu et al., 2013). At present, there are several methods to classify the occurrence forms of heavy metals in soil, and the most widely used and representative morphological analysis method is sequential extraction procedure (BCR) proposed by the European Community Bureau of Reference (Ure et al., 1993), which divides the element in soil or sediment into four fractions: the acid-exchangeable fraction (F1), reducible fraction (F2), oxidizable fraction (F3), and residual fraction (F4). Among them, cadmium associated with organic matter or sulfide (CdS) belong to the oxidizable fraction (F3). Rice is one of the most important cereal crops in the world and the main food crop in Asia (Carrijo et al., 2017). Because the paddy are continuously flooded or irrigated until 
harvesting, the soil is usually under anaerobic and reductive conditions. $S^{2-}$ produced in soil can deposit soluble $\mathrm{Cd}^{2+}$ in the form of $\mathrm{CdS}$, or transform the refractory $\mathrm{Cd}(\mathrm{OH})_{2}$ and $\mathrm{CdO}$ into more refractory sulfide, decreasing the mobility and bioavailability of $\mathrm{Cd}$.

CdS is also one of the widely used cadmium pigments with the band gap of $2.5 \mathrm{eV}$, which is highly photoactive under sunlight (Liu et al., 2017; Swafford et al., 2006). Upon illumination, photoelectrons are excited from their valence band to the conduction band of CdS, forming photoelectron-hole pairs and triggering a series of redox reaction. In previous studies, photocatalysis driven by CdS has received considerable attention as it can be used for environmental remediation and solar energy conversion (Mohan et al., 2021; Zhang et al., 2020). Furthermore, photo corrosion of CdS nanoparticles or quantum dots and subsequent release of $\mathrm{Cd}^{2+}$ ions have also been reported (Matsumoto et al., 1996).

Nevertheless, our understanding of the photo-transformation processes of CdS in soil under sunlight illumination is still limited. Such information reveals the presence of a photo-electrochemical system involved in the migration and transformation of $\mathrm{Cd}$ in paddy soils, which may increase the release risk of organic binding state $\mathrm{Cd}$.

Herein, in order to simulate CdS in natural soil, the montmorillonite was applied as a carrier to load the prepared CdS particles (CdS-M). The photo-mediated release of $\mathrm{Cd}^{2+}$ and $\mathrm{SO}_{4}{ }^{2-}$ from CdS was examined under simulated sunlight. The effect of factors including $\mathrm{pH}, \mathrm{DOM}$, phosphate, carbonate, urea, ferrous and ferric ion on the photo dissolution dynamics were further explored to inform the natural release process. Electron paramagnetic resonance (EPR) and quenching experiments were carried out to infer the possible mechanism of photo dissolution. In addition, the photo-mediated transformation of CdS in paddy samples was investigated under natural sunlight to support our findings.

\section{Materials And Methods}

\subsection{Chemicals}

In this research, all the chemical reagents were analytical grade or higher purity. Cadmium chloride $\left(\mathrm{CdCl}_{2} \cdot 2.5 \mathrm{H}_{2} \mathrm{O}\right)$, sodium sulfide $\left(\mathrm{Na}_{2} \mathrm{~S}\right)$, trisodium phosphate $\left(\mathrm{Na}_{3}\left(\mathrm{PO}_{4}\right)\right)$, sodium carbonate $\left(\mathrm{Na}_{2} \mathrm{CO}_{3}\right)$, montmorillonite (MMT), urea $\left(\mathrm{H}_{2} \mathrm{NCONH}_{2}\right)$, and other reagents were purchased from Sinopharm Chemical Reagent Co., Ltd, China. Both humic acid (HA) and fulvic acid (FA) were provided by Shanghai Macklin Biochemical Co.,Ltd. Methyl iologen dichloride hydrate $\left(\mathrm{MV}^{2+}\right)$ was obtained from Merck (Germany). All solutions were prepared using ultrapure water purfied by the Mili-Q system $(18 \mathrm{M} \Omega \mathrm{cm})$.

\subsection{Preparation of MMT loaded CdS}

The CdS-M composites were synthesized through the following steps: (i) Na-MMT was prepared by treating $9 \mathrm{~g}$ of MMT with $1 \mathrm{M} \mathrm{NaCl}$ solution under mechanical stirring for $24 \mathrm{~h}$. This procedure was repeated 5 times in order to obtain maximum saturation. Then, it was separated from the solution and washed several times with distilled water. (ii) The Na-MMT was mixed with $100 \mathrm{~mL}$ of $0.2 \mathrm{M} \mathrm{CdCl}_{2}$ 
solution for $2 \mathrm{~h}$ at $60^{\circ} \mathrm{C}$ in a magnetic mixer. The mixture was then separated from the suspension through centrifugation and rinsed with deionized water several times to remove the excess $\mathrm{Cd}^{2+}$. (iii) The $\mathrm{Cd}^{2+}{ }_{-}$MMT was redispersed in $100 \mathrm{~mL}$ of $0.2 \mathrm{~mol} / \mathrm{L} \mathrm{Na}_{2} \mathrm{~S}$ solution, and the mixture was stirred at $25^{\circ} \mathrm{C}$ for $2 \mathrm{~h}$. Clay particles in the solution immediately turned yellow. After that, the obtained CdS-M composites were centrifuged and rinsed three times with absolute ethanol, and then dried in $50^{\circ} \mathrm{C}$ oven under vacuum overnight. Dried samples were stored in an anaerobic chamber filled with pure $\mathrm{N}_{2}$ gas prior for use.

\subsection{Simulated illumination experiments}

Solar irradiation was simulated by a $50 \mathrm{~W}$ xenon lamp (CELHXF300, AULTT, China). The CdS-M stock suspension was prepared by dispersing $0.02 \mathrm{~g}$ CdS-M powder into $100 \mathrm{~mL}$ deionized water by ultrasonication for $2 \mathrm{~min}$, and then the resulting solution was placed in a water-circulating jacket beaker at $20 \pm 1^{\circ} \mathrm{C}$ and irradiated by the Xe lamp from the top without stir. The unadjusted $\mathrm{pH}$ of the suspension was $6.0 \pm 0.2$. At a regular interval, $5 \mathrm{~mL}$ sample was withdrawn from the beaker and filtered through a $0.22 \mu \mathrm{m}$-pore-size membrane filter to remove particles for further analysis. To guarantee precise data, all of the experiments were performed at least threefold and average values were recorded. Dark control experiments were carried out in the same experimental setting with the Xe lamp off and the beaker wrapped with aluminium foil.

The effect of $\mathrm{pH}$ on $\mathrm{Cd}^{2+}$ photo-mediated release was studied in the $\mathrm{pH}$ range of 3.98-8.11, with solutions adjusted using $0.1 \mathrm{M} \mathrm{HCl}$ and $\mathrm{NaOH}$. To examine the role of different reagents in the reactions, DOM, $\mathrm{PO}_{4}{ }^{3-}, \mathrm{CO}_{3}{ }^{2-}$, and urea were added in the simulated illumination experiments.

\subsection{Reactive oxygen species detection}

The generation of ROS by CdS under simulated solar irradiation was determined by electron paramagnetic resonance method (EPR, A300-10/12, Bruker, Germany) and quenching experiment. The EPR were tested at room temperature with a microwave power of $20 \mathrm{~mW}$, resonance frequency of 9.77 $\mathrm{GHz}$, center field of $3480 \mathrm{G}$, sweep width of $200 \mathrm{G}$, modulation frequency of $100 \mathrm{kHz}$, and modulation width of $1 \mathrm{G}$. The 5,5-dimethyl-1-pyrrolidine $\mathrm{N}$-oxide (DMPO) was used as a spin-trapping agent for $\cdot \mathrm{OH}$ and $\cdot \mathrm{O}_{2}{ }^{-}$, and the dimethyl sulfoxide (DMSO, 65\%) was used as the $\cdot \mathrm{OH}$ scavengers during the detection of $\cdot \mathrm{O}_{2}^{-}$.

The ROS involved in the photoreactions were examined via the quenching experiments using $\mathrm{Na}_{2} \mathrm{~S}_{2} \mathrm{O}_{3}$ as the hole scavenger, $\mathrm{MV}^{2+}$ as the electron scavenger, DMSO as the hydroxyl radical scavenger, and benzoquinone (BQ) as the peroxy radical scavenger.

\subsection{Soil illumination experiments}

To explore the effect of sunlight on soil Cd forms, the photo-mediated transformation of CdS in natural soil under sunlight was also examined. The soil samples were collected from a paddy field in Changsha, China $\left(113.10^{\circ} \mathrm{E}, 28.38^{\circ} \mathrm{N}\right)$ by five-spot sampling method. The depth of the topsoil was $0-20 \mathrm{~cm}$. Soil samples were air-dried, ground, sieved through a 2-mm nylon sieve. $50 \mathrm{~g}$ of soil sample were completely 
mixed with $0.2 \mathrm{~g}$ CdS-M composite, which was then added in a serum bottle and submerged by water (1:3 $\mathrm{w} / \mathrm{v})$. The serum bottles were sealed by microporous membrane filter and placed outdoors, while the bottles for dark control experiment were wrapped with aluminium foil and protected from light during the experiments. Three replicates were performed for each group. At the interval of every 3 days, the water and soil samples were taken out at 7 p.m. for analysis. Extractable $\mathrm{Cd}$ in soil was determined by diethylene triamine pentaacetic acid (DTPA) extraction by shaking for $16 \mathrm{~h}$ at $25^{\circ} \mathrm{C}$. BCR sequential chemical extraction was used to determine the different fractions of $\mathrm{Cd}$ in soil.

\subsection{Analytical method}

The $\mathrm{Cd}^{2+}$ concentration was detected by Optima 8300 ICP-OES (PerkinElmer, USA). The $\mathrm{SO}_{4}{ }^{2-}$ concentration was determined by ion chromatography (ICS-1000, Dionex, USA) with a Dionex IonPac AS11-HC analytical column $(250 \times 4 \mathrm{~mm})$. Reagent blanks and sample replicates were used to ensure analytical quality.

The phase composition and crystallinity of CdS-M composite were examined by X-ray diffractometer (XRD, Bruker D8-advance, Germany) with Cu-Ka radiation $(\lambda=1.5418 \AA$ ). The particles morphology was observed on a transmission electron microscopy (TEM, JEM-1230, JEOL, Japan). The surface chemistry of the CdS-M sample was examined using the X-ray photoelectron spectroscopy (XPS, ESCALAB 250XI, Thermo Scientific, USA) equipped with an Al KaX-ray radiation at $150 \mathrm{~W}$. The element composition of the CdS-M was determined via a FE-SEM (FEI, QUANTA250, USA) equipped with an energy-dispersive X-ray spectroscope (EDX).

\section{Results And Discussion}

\subsection{Characterization of CdS-M composites}

To confirm the successful incorporation of CdS in MMT, the crystalline structure of the MMT and CdS-M composites were characterized by XRD (Fig. 1). The main peak in the diffraction pattern of MMT $(2 \theta=$ $\left.5.9^{\circ}\right)$ can be attributed to the regular stacking of the silicate layers along the [001] direction, which is normal for montmorillonites (Krauskopf, 1967). The diffraction peaks occurring in the CdS-M composites at $2 \theta$ of $24.7^{\circ}, 26.3^{\circ}, 28.0^{\circ}, 43.3^{\circ}$ and $51.3^{\circ}$ were ascribed to the $\mathrm{Cd}$ [100], [002], [101], [110], and [112] planes, respectively, according to JCPDS file No. 41-1049 (Chen et al., 2020). Furthermore, compared to the natural MMT, that peak of the CdS-M was less obvious and some peaks have disappeared, which indicated the ordered layered structure of CdS-M was disrupted during loading.

The morphology and particle distribution of CdS on clay were analyzed by HR-TEM. Figure $2 a$ and $b$ provide the images of CdS-M samples containing some darker spots, the putative CdS particles with a few nanometers in diameter. Considering that the cation-exchange only occurred in the MMT layers, CdS oligomers mostly bound in the interlayers of clays, which were not distinguishable. The EDX elemental mapping of the CdS-M composites confirmed the presence of CdS on the MMT support (Fig. 2c). As shown in Fig. $2 \mathrm{~d}$, the HR-TEM image showed crystal spacings of 0.34 and $0.36 \mathrm{~nm}$ on the CdS-M 
composites, which were ascribed to the [002] and [100] crystal planes of the hexagonal CdS, respectively. Due to the distinct lattice fringes, CdS particles are easily differentiated from the clay background. EDX element analysis demonstrates that $\mathrm{Si}, \mathrm{Al}, \mathrm{Na}$, and $\mathrm{O}$ from the MMT are presented (Fig. 2e), and distinct peaks of $\mathrm{Cd}$ and $\mathrm{S}$ from the $\mathrm{CdS}$ are also observed. Quantitative analysis results revealed that the CdS-M composite contains $\mathrm{Cd}$ (12.92 wt.\%) and S (7.00 wt.\%).

The XPS was utilized to elucidate the chemical structure and composition of the CdS-M sample. In addition to the high response of $\mathrm{Al}$ and $\mathrm{Si}$ in montmorillonite, $\mathrm{Cd} 3 \mathrm{~d}$ and $\mathrm{S} 2 \mathrm{p}$ signals were detected in the XPS spectra (Fig. 3a). The deconvoluted high-resolution spectra showed double peaks at $411.4 \mathrm{eV}(\mathrm{Cd}$ $\left.3 \mathrm{~d}_{3 / 2}\right)$ and $404.7 \mathrm{eV}\left(\mathrm{Cd} 3 \mathrm{~d}_{5 / 2}\right)$, which were considered the characteristic peaks of the $\mathrm{Cd}^{2+}$ species, whereas the peaks at $168.6 \mathrm{eV}\left(\mathrm{S} 2 \mathrm{p}_{1 / 2}\right)$ and $161.1\left(\mathrm{~S} 2 \mathrm{p}_{3 / 2}\right)$ were assigned to the spin-orbit double of $\mathrm{S}^{2-}$ (Fig. 3b and c) (Huang et al., 2018). As a result, the characterization by XRD, TEM, EDX and XPS verified that the CdS was loaded into the MMT layers successfully with the procedures.

\subsection{Release kinetics of $\mathrm{Cd}^{2+}$ from CdS-M composite}

The release of $\mathrm{Cd}^{2+}$ and $\mathrm{SO}_{4}{ }^{2-}$ from the CdS-M composite was examined under both dark and simulated solar irradiation (Fig. $4 \mathrm{a}$ and b). There are small amount of $\mathrm{Cd}^{2+}$ and $\mathrm{SO}_{4}{ }^{2-}$ release from the CdS-M suspension in the dark condition within $240 \mathrm{~min}$, which can be ascribed to the ions release during the dispersion process by sonication. This indicated an insignificant oxidative dissolution of CdS in the dark condition. In contrast, the presence of simulated solar irradiation was found to lead to significant and continuous enhance in the release of $\mathrm{Cd}^{2+}$ and $\mathrm{SO}_{4}{ }^{2-}$ in the solution. The concentration of $\mathrm{Cd}^{2+}$ increased to $7.60 \pm 0.38 \mathrm{mg} / \mathrm{L}$ within a 100 -mins irradiation, and to $9.11 \pm 0.23 \mathrm{mg} / \mathrm{L}$ after 240 mins of irradiation; meanwhile, the concentration of $\mathrm{SO}_{4}{ }^{2-}$ reached $20.09 \pm 0.30 \mathrm{mg} / \mathrm{L}$ at the end of the test.

The release kinetics of $\mathrm{Cd}^{2+}$ can be well described by the pseudo-second order equation. The pseudosecond-rate constants $(k, \mathrm{~L} / \mathrm{mmol} \cdot \mathrm{h})$ was determined by fitting data to the following kinetic equation:

$$
\frac{1}{[C d S]_{t}}-\frac{1}{[C d S]_{0}}=k t
$$

The calculated $k$ of $\mathrm{Cd}^{2+}$ was $0.126 \mathrm{~L} / \mathrm{mmol} \cdot \mathrm{h}\left(R^{2}=0.97\right)$, which was 6.3 times higher than that under dark condition $\left(k=0.020 \mathrm{~L} / \mathrm{mmol} \cdot \mathrm{h}, R^{2}=0.90\right.$ ). These results revealed that sunlight played a key role in promoting the release of $\mathrm{Cd}^{2+}$ from CdS.

\subsection{Mechanisms for the photo dissolution of CdS}

The EPR and radicals quenching experiments were carried out to detect the photo transients (such as $\cdot \mathrm{OH}$ and $\mathrm{O}_{2}$, etc.) generated by the CdS under simulated solar irradiation. The EPR spectrum of the CdS under irradiation showed a six-lines signals with the intensity ratio of 1:1:1:1:1:1 (Fig. 5a), which is the hallmark for the DMPO.0O(H) adduct, confirming the formation of $\cdot \mathrm{O}_{2}{ }^{-}$(Fang et al., 2017). As illustrated in Fig. $5 \mathrm{~b}$, 
the characteristic intensity 1:2:2:1 of the DMPO-OH adduct was observed in the CdS suspension under simulated solar, suggesting the generation of $\cdot \mathrm{OH}$ (Makino et al., 1991). Additionally, there were no EPR peaks in the same sample without simulated solar irradiation.

As previously reported by Gu et al. (Gu et al., 2015), the band gap energy ( $\left.E_{g}\right)$ of CdS was $2.4 \mathrm{eV}$, and its conduction and valence bands (CB and VB) edge potentials are located at about -0.505 and $+1.895 \mathrm{eV}$, respectively. Therefore, $\mathrm{CdS}$ could be excited by the visible-light irradiation and produce the photogenerated electron-hole pairs (Eqs. (1)). The CB potential of CdS is more negative than the redox potential of $\mathrm{O}_{2} / \mathrm{O}_{2}{ }^{-}(-0.33 \mathrm{eV})$, indicating the agminated electrons in the $\mathrm{CB}$ can reduce $\mathrm{O}_{2}$ into $\mathrm{O}_{2}{ }^{-{ }^{--}}$and other active species (Eqs. (2), (3) and (4)). Meanwhile, the photogenerated holes in the VB of CdS is not positive enough to oxidize $\mathrm{H}_{2} \mathrm{O}$ or $\mathrm{OH}^{-}$into $\cdot \mathrm{OH}\left(\cdot \mathrm{OH} / \mathrm{H}_{2} \mathrm{O}=+2.27 \mathrm{eV} ; \cdot \mathrm{OH} / \mathrm{OH}^{-}=+1.99 \mathrm{eV}\right.$, respectively) (Luo et al., 2017). In consequence, the formation of $\cdot \mathrm{OH}$ was most likely generated through the $\mathrm{H}_{2} \mathrm{O}_{2}$ reduction pathway (Eqs. (5) and (6)).

$$
\begin{aligned}
& \mathrm{CdS}_{\mathrm{x}} \mathrm{Se}_{1-\mathrm{x}} \stackrel{(0<596 \mathrm{~nm})}{\longrightarrow} \mathrm{e}^{-}+\mathrm{h}^{+} \\
& \mathrm{e}^{-}+\mathrm{O}_{2} \rightarrow \mathrm{O}_{2}{ }^{--} \\
& 2 \mathrm{O}_{2}{ }^{\bullet-}+2 \mathrm{H}^{+} \rightarrow \mathrm{H}_{2} \mathrm{O}_{2}+\mathrm{O}_{2} \\
& \mathrm{H}_{2} \mathrm{O}_{2}+\mathrm{e}^{-} \rightarrow \bullet \mathrm{OH}+\mathrm{OH}^{-} \\
& \mathrm{H}_{2} \mathrm{O}_{2}+\mathrm{O}_{2}{ }^{--} \rightarrow \bullet \mathrm{OH}+\mathrm{OH}^{-}+\mathrm{O}_{2} \\
& \mathrm{H}_{2} \mathrm{O}_{2} \stackrel{\text { hv }}{\longrightarrow} 2 \bullet \mathrm{OH}
\end{aligned}
$$

To determine the contribution of holes, electrons, $\cdot \mathrm{OH}$, and $\cdot \mathrm{O}_{2}{ }^{-}$, scavengers including $\mathrm{Na}_{2} \mathrm{~S}_{2} \mathrm{O}_{3}, \mathrm{MV}^{2+}$, DMSO and $\mathrm{BQ}$ were added into the CdS-MMT photoreaction system, respectively. As shown in Fig. $5 \mathrm{c}$, the photodissolution of $\mathrm{CdS}$ under simulated solar were all inhibited after the addition of $\mathrm{Na}_{2} \mathrm{~S}_{2} \mathrm{O}_{3}, \mathrm{DMSO}$ and $B Q$, which decreased from $9.11 \mathrm{mg} / \mathrm{L}$ to $3.04,7.38$ and $5.54 \mathrm{mg} / \mathrm{L}$, respectively, after $240 \mathrm{mins}$. However, the presence of $\mathrm{MV}^{2+}$ exerted an obviously promoting effect on the photodissolution of $\mathrm{Cd}^{2+}$. $\mathrm{MV}^{2+}$ can react with photogenerated electrons, reducing the recombination probability of photogenerated electron-hole pairs and consequently leaving more holes involved in the photocatalysis system. This is consistent with the observations in the previous studies (Liu et al., 2017; Matsumoto et al., 1996). Furthermore, the photodissolution of CdS was also significantly inhibited under the anaerobic condition. Deficient oxygen can not combine with electrons to yield $\cdot \mathrm{O}_{2}^{-}$, leading to more electron recombined with the holes and the inhibited release of $\mathrm{Cd}^{2+}$ accordingly. The above results showed that the photogenerated reactive species $\left(h^{+}, \mathrm{O}_{2}^{-\cdots} \cdot \mathrm{OH}^{-}\right.$etc) were possibly involved in the photo-induced release of 
$\mathrm{Cd}^{2+}$ (Ge et al., 2015; Hu et al., 2018; Liu et al., 2017; Liu et al., 2020; Zhang et al., 2018), while the reaction was predominated by the holes. Based on these, the possible mechanism for the solar-mediated $\mathrm{Cd}^{2+}$ release from CdS is as follows (Eqs. (7)-(9)):

$$
\begin{aligned}
& \mathrm{CdS}+4 h^{+}+\mathrm{O}_{2}+2 \mathrm{H}_{2} \mathrm{O} \stackrel{m v}{\longrightarrow} \mathrm{Cd}^{2+}+\mathrm{SO}_{4}^{2-}+4 \mathrm{H}^{+} \\
& \mathrm{CdS}+2 \bullet \mathrm{OH}+2 \mathrm{H}_{2} \mathrm{O} \stackrel{h v}{\longrightarrow} \mathrm{Cd}^{2+}+\mathrm{SO}_{4}^{2-}+8 \mathrm{H}^{+} \\
& \mathrm{CdS}+2 \bullet \mathrm{O}_{2}^{-}+2 \mathrm{H}_{2} \mathrm{O} \stackrel{m}{\longrightarrow} \mathrm{Cd}^{2+}+\mathrm{SO}_{4}^{2-}+4 \mathrm{H}^{+}
\end{aligned}
$$

\subsection{Influence of environmental factors on the photodissolution of CdS}

To further understand the environmentally realistic release process, the effects of environmental factors including $\mathrm{pH}, \mathrm{DOM}, \mathrm{PO}_{4}{ }^{3-}, \mathrm{CO}_{3}{ }^{2-}$ and urea on the photodissolution of $\mathrm{CdS}$ were examined.

\subsection{1 pH}

As is shown in Fig. 6a, the solution pH has an important effect on the photolysis of CdS. The photodissolution rate increased with increasing the initial pH in acidic conditions (from 3.98 to 6.00), yet the photodissolution drastically decreased as the initial $\mathrm{pH}$ increased to 8.11. Under alkaline conditions, the formation of $\mathrm{Cd}(\mathrm{OH}) 2$ precipitates $\left(K_{s p}, \mathrm{Cd}(\mathrm{OH})_{2}=7.2 \times 10^{-15}\right)$ (Lide, 2004) or adsorption of $\mathrm{OH}^{-}$on the CdS-M surfaces (Torimoto et al., 1998) could effectively blocked the sites for trapping holes, leading to higher recombination of photogenerated electron-hole pairs and consequently less reaction with trapped holes (Spanhel et al., 1987). On the other hand, as the pH increased from 6.00 to 8.11, the VB edge of CdS was also decreased, resulting in the reduced photooxidation of CdS and inhibited photoinduced release of $\mathrm{Cd}^{2+}$ in the solution. Accordingly, the impact of initial $\mathrm{pH}$ on the photodissolution of CdS further supported the proposed mechanism of hole predomination.

\subsubsection{DOM}

The presence of DOM in natural waters (usually more than $2 \%$ ) plays an important role in the fate and transformation of metal ions through direct complexation or activization, or oxidation with photogenerated ROS (Li et al., 2014; Pokhrel et al., 2014). To explore the effect of DOM on the photodissolution of CdS, experiments were conducted in the presence of $5 \mathrm{mg} \mathrm{C/L} \mathrm{HA} \mathrm{and} \mathrm{FA.} \mathrm{A} \mathrm{DOM-}$ mediated inhibition of $\mathrm{Cd}^{2+}$ release can be observed in Fig. 6b, especially in the presence of FA. The inhibition effect could be ascribed to three possible mechanisms: (i) HA and FA molecules could absorb the light energy due to their photosensitivity and then reduced the receipt of irradiation by CdS (Xue et al., 2021); (ii) The complex formed by DOM and Cd could control the stability of Cd (Jia et al., 2019); (iii) HA 
and FA could also compete for the photons and holes, mitigating the oxidation dissolution of CdS. However, photoactive DOM can generate ROS, which could promote the photo-oxidation of CdS. The overall effect of DOM depended on the interplay of the above mechanisms.

\subsection{3 $\mathrm{PO}_{4}{ }^{3-}$ and $\mathrm{CO}_{3}{ }^{2-}$}

Phosphate and carbonate are well-known abundant anions in environmental media, which could affected the photo-oxidation process. Significantly inhibited release of $\mathrm{Cd}^{2+}$ was observed during simulated solar irradiation with the addition of $10 \mathrm{mg} / \mathrm{L} \mathrm{PO}_{4}{ }^{3-}$ or $\mathrm{CO}_{3}{ }^{2-}$ (Fig. $6 \mathrm{c}$ ). Especially, in the presence of $\mathrm{CO}_{3}{ }^{2-}$, the concentration of $\mathrm{Cd}^{2+}$ remained between $0.4 \mathrm{mg} / \mathrm{L}$ and $0.7 \mathrm{mg} / \mathrm{L}$, much lower than that of the control. The main inhibition mechanism is the formation of insoluble and photostable $\mathrm{Cd}_{3}\left(\mathrm{PO}_{4}\right)_{2}$ and $\mathrm{CdCO}_{3}$ salts $\left(K_{s p}, \mathrm{Cd}_{3}\left(\mathrm{PO}_{4}\right)_{2}=2.5 \times 10^{-33}\right.$, and $\left.K_{s p}, \mathrm{Cd} \mathrm{CO}_{3}=5.7 \times 10^{-13}\right)$ (Jia et al., 2019), which cannot be oxidized by photogeneration holes or ROS in solution. Meanwhile, the solution $\mathrm{pH}$ value would increase correspondingly by the addition of $\mathrm{PO}_{4}{ }^{3-}$ and $\mathrm{CO}_{3}{ }^{2-}$, generating cadmium hydroxide precipitation under alkaline conditions consequent affecting the photolysis of CdS (Luo et al., 2017; Matsumoto et al., 1996). Therefore, the passivation of the CdS surface by the cadmium salts or cadmium hydroxide precipitation leaded to the inhibited release of $\mathrm{Cd}^{2+}$. Phosphate and carbonate played a negative role in photodissolution of CdS.

\subsubsection{Urea}

Urea is the most commonly used nitrogen fertilizer in rice production in South China. Figure $6 \mathrm{~d}$ showed that the release rate of $\mathrm{Cd}^{2+}$ from CdS was markedly inhibited with the addition of $2 \mathrm{mmol} / \mathrm{L}$ urea. It has been documented that urea and $\mathrm{N}$-containing compounds could be photodegraded in aqueous solutions under near-UV or visible radiation using the catalysts (such $\mathrm{TiO}_{2}$ and so on), forming $\mathrm{NH}_{4}{ }^{+}$and $\mathrm{NO}_{3}{ }^{-}$ions (Makino et al., 1991; Nohara et al., 1997). Furthermore, the photocomposition of urea was mainly attributed to the generated $\cdot \mathrm{OH}$ in the system as a strong oxidant. The competition of $\cdot \mathrm{OH}$ appears to explain the inhibition effects of urea on the photodissolution of CdS. Therefore, the release of $\mathrm{Cd}^{2+}$ should be slower in water with the application of urea.

\subsection{Photo-mediated transformation of CdS in soil under sunlight}

In order to obtain further insight into the natural photodissolution process of CdS in soil, a solar irradiation experiment of paddy topsoil sample was performed on the campus of Hunan Agricultural University from 27/08/2020-10/09/2020. The basic physical and chemical properties of the soil were introduced in Table 1. 
Table 1

Physico-chemical properties of the tested soil sample
Soil typ
$\mathrm{pH}$
$\mathrm{CEC}(\mathrm{cmol}(+) / \mathrm{kg})$
Organic matter $(\mathrm{g} / \mathrm{kg})$
Total Cd (mg/kg)
Total $\mathbf{N}$

$(\mathrm{g} / \mathrm{kg})$

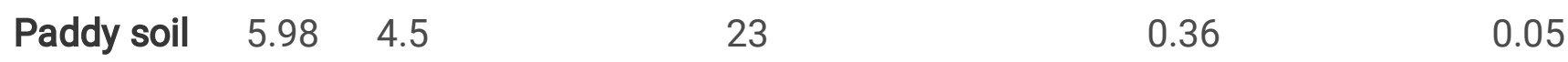

\subsubsection{Concentrations of soil extractable $\mathrm{Cd}$ and $\mathrm{Cd}^{2+}$ in surface water}

Figure 7a shows the concentrations of DTPA-extractable $\mathrm{Cd}$ in the topsoil sampled on days 3, 6, 9, 12 and 15. In natural solar irradiation group, the contents of extractable $\mathrm{Cd}$ in soil increased markedly with time, nevertheless, there were insignificant changes of extractable $\mathrm{Cd}$ under the dark condition. Meanwhile, enhanced release of $\mathrm{Cd}^{2+}$ was observed in the surface water sample under solar condition (Fig. 7b), while the increase of $\mathrm{Cd}^{2+}$ under dark was slight. During the 15 days irradiation, the concentrations of DTPAextractable Cd in soil increased from $0.81 \mathrm{mg} / \mathrm{kg}$ to $2.18 \mathrm{mg} / \mathrm{kg}$. The above results indicate that sunlight plays an important role in the mobility and bioavailability of $\mathrm{Cd}$ in natural soil even in waterlogged paddy soil, which might be attributed to the photodissolution of CdS in topsoils. Furthermore, the soil pH increased and Eh decreased in both of the light and dark groups, the first day been taken as a control (Fig. S1). These changes could be related to the waterlogging treatment, and similar results have been reported in previous study (Zhang et al., 2019).

\subsubsection{Distribution of Cd fractions in soils}

The distributions of $\mathrm{Cd}$ among different fractions in the soil are presented in Fig. 8. The acid-extractable fraction (F1) Cd has the greatest mobility and bioavailability, whereas the residual fraction (F4) Cd is the most stable form and was unavailable to biota. The reducible fraction (F2) is mainly consist of Cd bound to amorphous Fe-Mn oxides and hydroxides, whereas the oxidizable fraction (F3) Cd is predominantly associated with organic matter and sulfides (Wang et al., 2021).

As shown in Fig. 8, acid-extractable Cd was the largest fraction, followed by the oxidizable, residual and reducible fraction. F1 accounted for $42.49 \%$ and $34.97 \%$ of $\mathrm{Cd}$ in light group and dark group soil samples, respectively, compared to $38.92 \%$ in initial soil. The proportions of the oxidizable and residual $\mathrm{Cd}$ fractions in three soil samples were similar. Notably, the reducible fraction in light group (20.76\%) was lower than that in the initial soil (23.45\%), indicating the transformation of Cd associated with organic matter and sulfides to other fractions in soils under natural sunlight. These results showed that the $\mathrm{Cd}$ fractions was affected by solar irradiation, as the acid-extractable Cd increased, whereas the oxidizable $\mathrm{Cd}$ decreased in the light group. It was suggested that natural sunlight can activate soil $\mathrm{Cd}$ and increase its bioavailability and environmental risk. Moreover, the waterlogging treatment can reduce the $\mathrm{Cd}$ mobility in soil, consistent with previous observations (Zhang et al., 2019).

\section{Conclusions}


$\mathrm{CdS}$ is a stable form of $\mathrm{Cd}$ in natural soil environments, which belongs to the oxidizable fraction. We herein investigated the effect of the sunlight on the $\mathrm{Cd}$ stability and activity. The kinetic experiments showed that simulated solar irradiation enhanced the release of $\mathrm{Cd}^{2+}$ from CdS-M significantly. The $\mathrm{Cd}^{2+}$ release rate increased from 3.98 to 6.00 , while drastically decreased as the initial pH increased to 8.11 . In addition, all of the co-existing $\mathrm{DOM}, \mathrm{PO}_{4}{ }^{3-}, \mathrm{CO}_{3}{ }^{2-}$ and urea negatively affected the photodissolution of $\mathrm{CdS}$ in solution. The possible mechanism of the solar-mediated $\mathrm{Cd}^{2+}$ release from CdS was predominated by the holes, besides, the photogenerated $\mathrm{O}_{2}{ }^{--}$and $\cdot \mathrm{OH}$ were also possibly involved in the photo-induced reaction. The soil illumination experiment results showed that natural sunlight can activate soil Cd, lead to the increase of its bioavailability and environmental risk. These findings indicate that the solar irradiation may play an important role in shaping $\mathrm{Cd}$ species, to increase its mobility and bioavaibility in natural soils. However, the irradiation exposure was only performed in laboratory settings under simulated conditions. The complexity of the environmental medium calls for studies under field or field-like conditions.

\section{Declarations}

\section{Availability of data and materials}

The datasets used and analyzed during the current study are available from the corresponding author on reasonable request.

\section{Ethical Approval and Consent to Participate}

Not applicable.

\section{Consent for publication}

Not applicable.

\section{Competing Interests}

The authors declare no competing interests.

\section{Authors Contribution}

Bihao Luo: Conceptualization, Methodology, Software, Investigation

Chenfeng Xiao: Data curation, Writing- original draft preparation.

Yuling Liu: Validation, Formal analysis, Visualization.

Li Li: Validation, Formal analysis, Visualization.

Liang Peng: Software, Writing - Review \& Editing, Supervision. 
Qingru Zeng: Software, Writing - Review \& Editing, Supervision.

Si Luo: Funding acquisition, Writing-review \& editing, Supervision.

All authors have reviewed and approved the final version for submission.

\section{Funding}

This research was supported by the Key Research and Development Program of Hunan Province (2022NK2014), the Hunan Provincial Natural Science Foundation of China (No. 13JJ4069), and the High Technology Industry S\&T Innovation Leading Project of Hunan Province (No. 2020NK2001).

\section{References}

1. Carrijo, D.R., Lundy, M.E., Linquist, B.A., 2017. Rice yields and water use under alternate wetting and drying irrigation: A meta-analysis. Field Crops Research 203, 173-180.

2. Chen, Z., Xing, R., Tang, J., Chen, Z., Zhang, Z., Liao, H., Huang, R., Wei, D., Zhou, S., 2020. Upcycling of Cd Hyperaccumulator Biomass into a CdS@C Nanocomposite with High Photocatalytic Performance. ACS Sustainable Chemistry \& Engineering 8, 1388-1395.

3. Fang, G., Liu, C., Wang, Y., Dionysiou, D.D., Zhou, D., 2017. Photogeneration of reactive oxygen species from biochar suspension for diethyl phthalate degradation. Applied Catalysis B: Environmental 214, 34-45.

4. Ge, L., Gong, X., Wang, Z., Zhao, L., Wang, Y., Wang, M., 2015. Sulfur removal from bauxite water slurry (BWS) electrolysis intensified by ultrasonic. Ultrasonics Sonochemistry 26, 142-148.

5. Gu, S., Chen, Y., Yuan, X., Wang, H., Chen, X., Liu, Y., Jiang, Q., Wu, Z., Zeng, G., 2015. Facile synthesis of $\mathrm{CeO} 2$ nanoparticle sensitized $\mathrm{CdS}$ nanorod photocatalyst with improved visible-light photocatalytic degradation of rhodamine B. RSC Advances 5, 79556-79564.

6. Hu, Y., Zhang, T., Gong, X., Wang, Z., Wang, M., Zhang, S., 2018. Roles of Ultrasound on Hydroxyl Radical Generation and Bauxite Desulfurization from Water Electrolysis. Journal of The Electrochemical Society 165, E177-E183.

7. Huang, H.-B., Wang, Y., Jiao, W.-B., Cai, F.-Y., Shen, M., Zhou, S.-G., Cao, H.-L., Lü, J., Cao, R., 2018. Lotus-Leaf-Derived Activated-Carbon-Supported Nano-CdS as Energy-Efficient Photocatalysts under Visible Irradiation. ACS Sustainable Chemistry \& Engineering 6, 7871-7879.

8. Jia, Y., Zhao, T., Zhao, N., Wei, H., Zhang, W., Qiu, R., 2019. Effects of light irradiation on the complexes of cadmium and humic acids: The role of thiol groups. Chemosphere 225, 174-181.

9. Krauskopf, K.B., 1967. INTERNATIONAL SERIES IN THE EARTH AND PLANETARY SCIENCES.

10. Li, Y., Niu, J., Shang, E., Crittenden, J., 2014. Photochemical Transformation and Photoinduced Toxicity Reduction of Silver Nanoparticles in the Presence of Perfluorocarboxylic Acids under UV Irradiation. Environmental Science \& Technology 48, 4946-4953.

11. Lide, D.R., 2004. Handbook of Chemistry Physics 85th edn. C.R.C. 
12. Liu, H., Gao, H., Long, M., Fu, H., Alvarez, P.J.J., Li, Q., Zheng, S., Qu, X., Zhu, D., 2017. Sunlight Promotes Fast Release of Hazardous Cadmium from Widely-Used Commercial Cadmium Pigment. Environmental Science \& Technology 51, 6877-6886.

13. Liu, S., Li, X., Zhang, H., 2020. Synergistic effects of MOF-76 on layered double hydroxides with superior activity for extractive catalytic oxidative desulfurization. New Journal of Chemistry 44, 62696276.

14. Lu, R.K., 2000. Methods for soil agrochemistry analysis.

15. Luo, S., Wang, F., Yu, K., Shao, J., Peng, L., Zeng, Q., 2017. Enhancement of visible-light photocatalytic activity of Cu3B206 hybridized with g-C3N4. Colloids and Surfaces A: Physicochemical and Engineering Aspects 520, 409-419.

16. Mahar, A., Wang, P., Ali, A., Awasthi, M.K., Lahori, A.H., Wang, Q., Li, R., Zhang, Z., 2016. Challenges and opportunities in the phytoremediation of heavy metals contaminated soils: A review. Ecotoxicology and Environmental Safety 126, 111-121.

17. Makino, K., Hagiwara, T., Murakami, A., 1991. A mini review: Fundamental aspects of spin trapping with DMPO. International Journal of Radiation Applications and Instrumentation. Part C. Radiation Physics and Chemistry 37, 657-665.

18. Matsumoto, H., Sakata, T., Mori, H., Yoneyama, H., 1996. Preparation of Monodisperse CdS Nanocrystals by Size Selective Photocorrosion. The Journal of Physical Chemistry 100, 1378113785.

19. Mohan, H., Ramalingam, V., Karthi, N., Malathidevi, S., Shin, T., Venkatachalam, J., Seralathan, K.-K., 2021. Enhanced visible light-driven photocatalytic activity of reduced graphene oxide/cadmium sulfide composite: Methylparaben degradation mechanism and toxicity. Chemosphere 264, 128481.

20. Niu, L., Yang, F., Xu, C., Yang, H., Liu, W., 2013. Status of metal accumulation in farmland soils across China: from distribution to risk assessment. Environ Pollut 176, 55-62.

21. Nohara, K., Hidaka, H., Pelizzetti, E., Serpone, N., 1997. Processes of formation of NH4+ and NO3ions during the photocatalyzed oxidation of $\mathrm{N}$-containing compounds at the titania/water interface. Journal of Photochemistry and Photobiology A: Chemistry 102, 265-272.

22. Pokhrel, L.R., Dubey, B., Scheuerman, P.R., 2014. Natural water chemistry (dissolved organic carbon, $\mathrm{pH}$, and hardness) modulates colloidal stability, dissolution, and antimicrobial activity of citrate functionalized silver nanoparticles. Environ. Sci.: Nano 1, 45-54.

23. Saini, S., Dhania, G., 2020. Cadmium as an Environmental Pollutant: Ecotoxicological Effects, Health Hazards, and Bioremediation Approaches for Its Detoxification from Contaminated Sites, in: Bharagava, R.N., Saxena, G. (Eds.), Bioremediation of Industrial Waste for Environmental Safety: Volume II: Biological Agents and Methods for Industrial Waste Management. Springer Singapore, Singapore, pp. 357-387.

24. Spanhel, L., Haase, M., Weller, H., Henglein, A., 1987. Photochemistry of colloidal semiconductors. 20. Surface modification and stability of strong luminescing CdS particles. Journal of the American Chemical Society 109, 5649-5655. 
25. Swafford, L.A., Weigand, L.A., Bowers, M.J., McBride, J.R., Rapaport, J.L., Watt, T.L., Dixit, S.K., Feldman, L.C., Rosenthal, S.J., 2006. Homogeneously Alloyed CdSxSe1-x Nanocrystals: Synthesis, Characterization, and Composition/Size-Dependent Band Gap. Journal of the American Chemical Society $128,12299-12306$.

26. Torimoto, T., Nishiyama, H., Sakata, T., Mori, H., Yoneyama, H., 1998. Characteristic Features of SizeSelective Photoetching of CdS Nanoparticles as a Means of Preparation of Monodisperse Particles. Journal of The Electrochemical Society 145, 1964-1968.

27. Ure, A.M., Quevauviller, P., Muntau, H., Griepink, B., 1993. Speciation of Heavy Metals in Soils and Sediments. An Account of the Improvement and Harmonization of Extraction Techniques Undertaken Under the Auspices of the BCR of the Commission of the European Communities. International Journal of Environmental Analytical Chemistry 51, 135-151.

28. Wang, F., Peng, L., Zhou, X., Zeng, Q., Luo, S., 2021. Typical sources of Cd to paddy fields in different contaminated areas and their impacts on $\mathrm{Cd}$ accumulation in topsoil and rice in Changzhutan, China. Environmental Research 193, 110523.

29. Xue, C., Peng, Y., Chen, A., Peng, L., Luo, S., 2021. Drastically inhibited nZVI-Fenton oxidation of organic pollutants by cysteine: Multiple roles in the $\mathrm{nZVI/O2/hv} \mathrm{system.} \mathrm{Journal} \mathrm{of} \mathrm{Colloid} \mathrm{and}$ Interface Science 582, 22-29.

30. Zhang, D., Du, G., Chen, D., Shi, G., Rao, W., Li, X., Jiang, Y., Liu, S., Wang, D., 2019. Effect of elemental sulfur and gypsum application on the bioavailability and redistribution of cadmium during rice growth. Science of The Total Environment 657, 1460-1467.

31. Zhang, J., Yuan, X., Si, M., Jiang, L., Yu, H., 2020. Core-shell structured cadmium sulfide nanocomposites for solar energy utilization. Advances in Colloid and Interface Science 282, 102209.

32. Zhang, T., Hu, Y., Zhou, Y., Gong, X., Wang, Z., Zhang, S., Wang, M., 2018. Oxygen Reduction Reaction from Water Electrolysis Intensified by Pressure and 02-Oxidation Desulfurization. Journal of The Electrochemical Society 165, E139-E147.

\section{Figures}




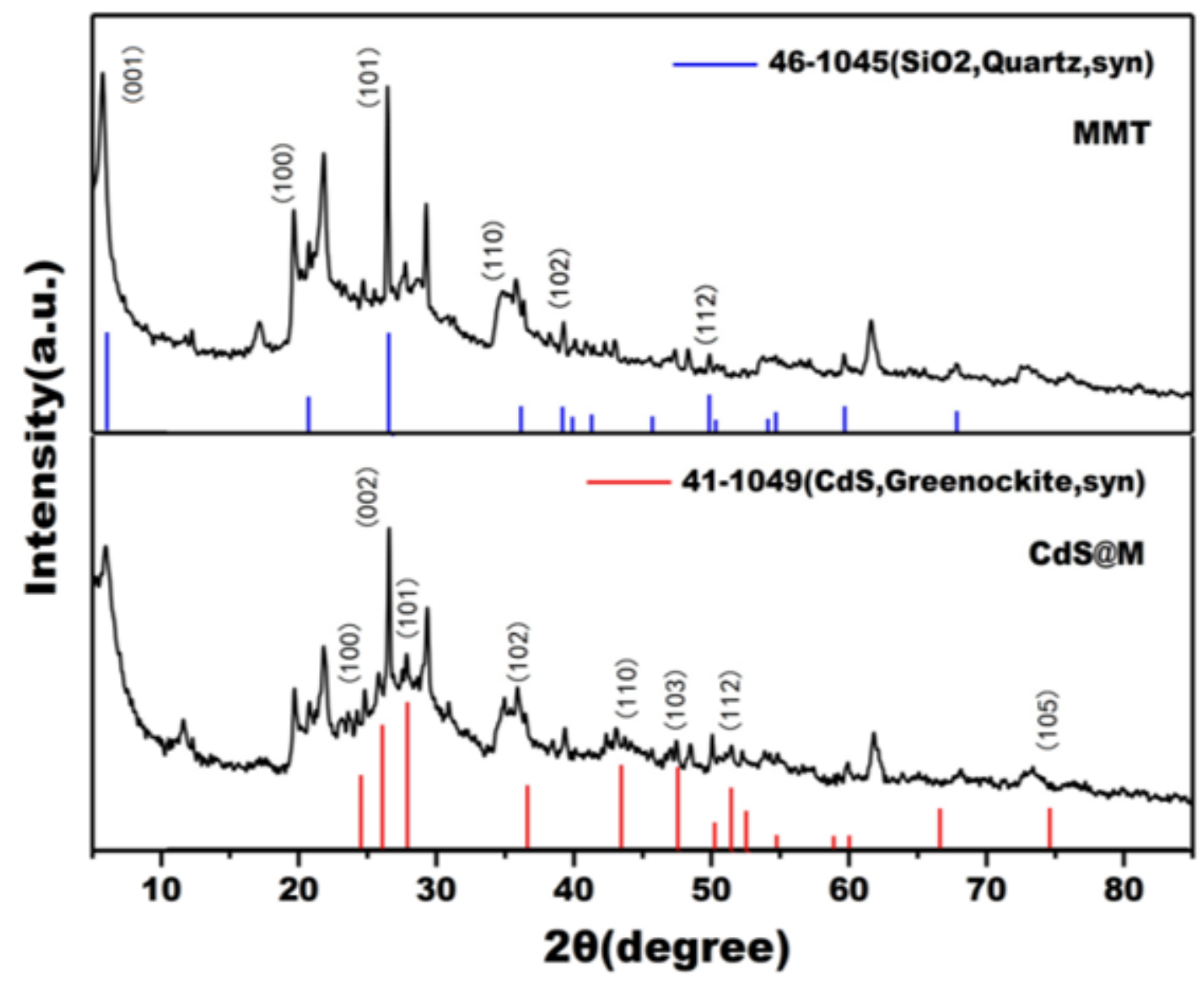

Figure 1

XRD patterns of the MMT and CdS-M composites 

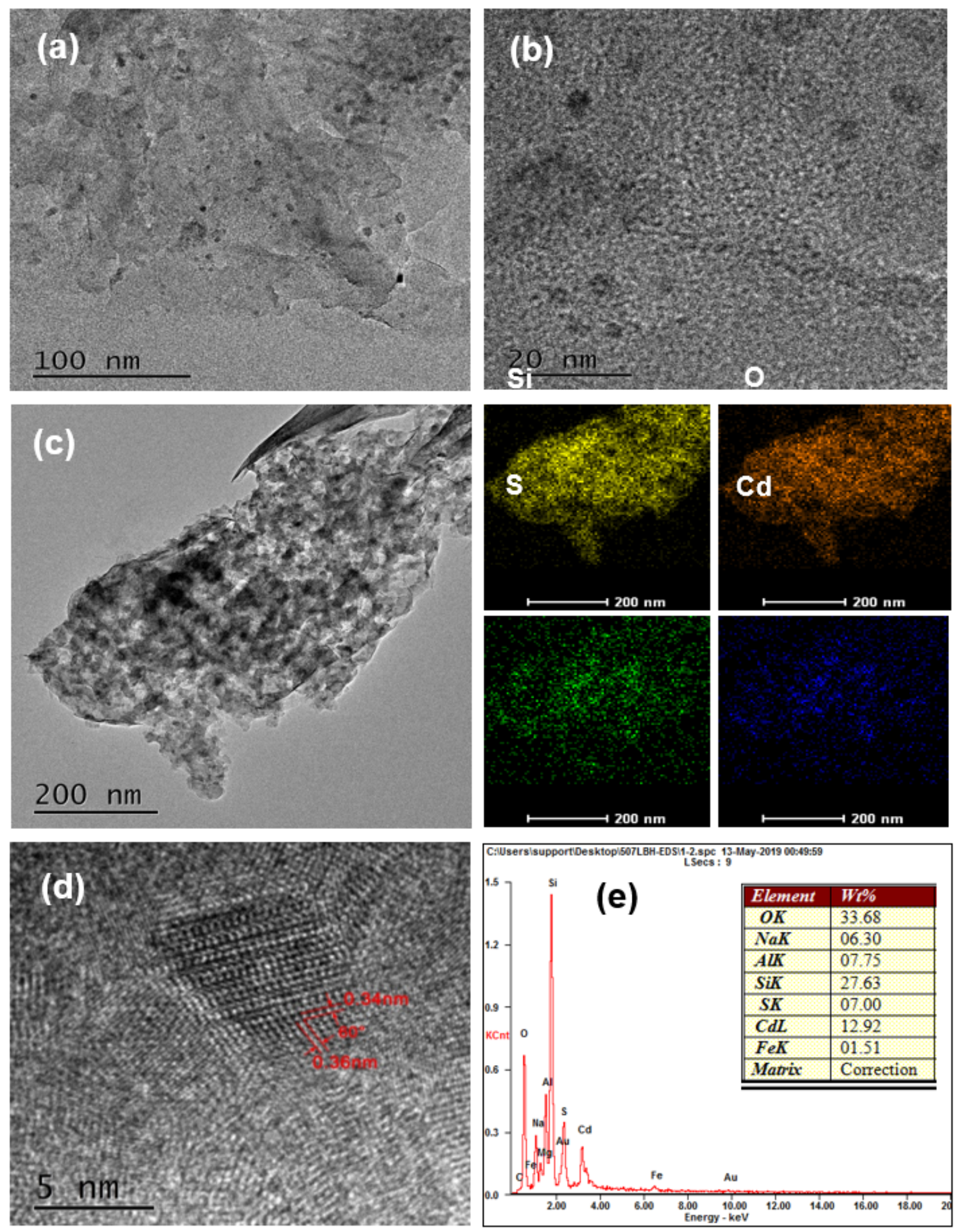

\section{Figure 2}

(a-c) TEM images and EDX elemental mapping of CdS-M; (d) HR-TEM images and (e) EDX analysis results of CdS-M. 

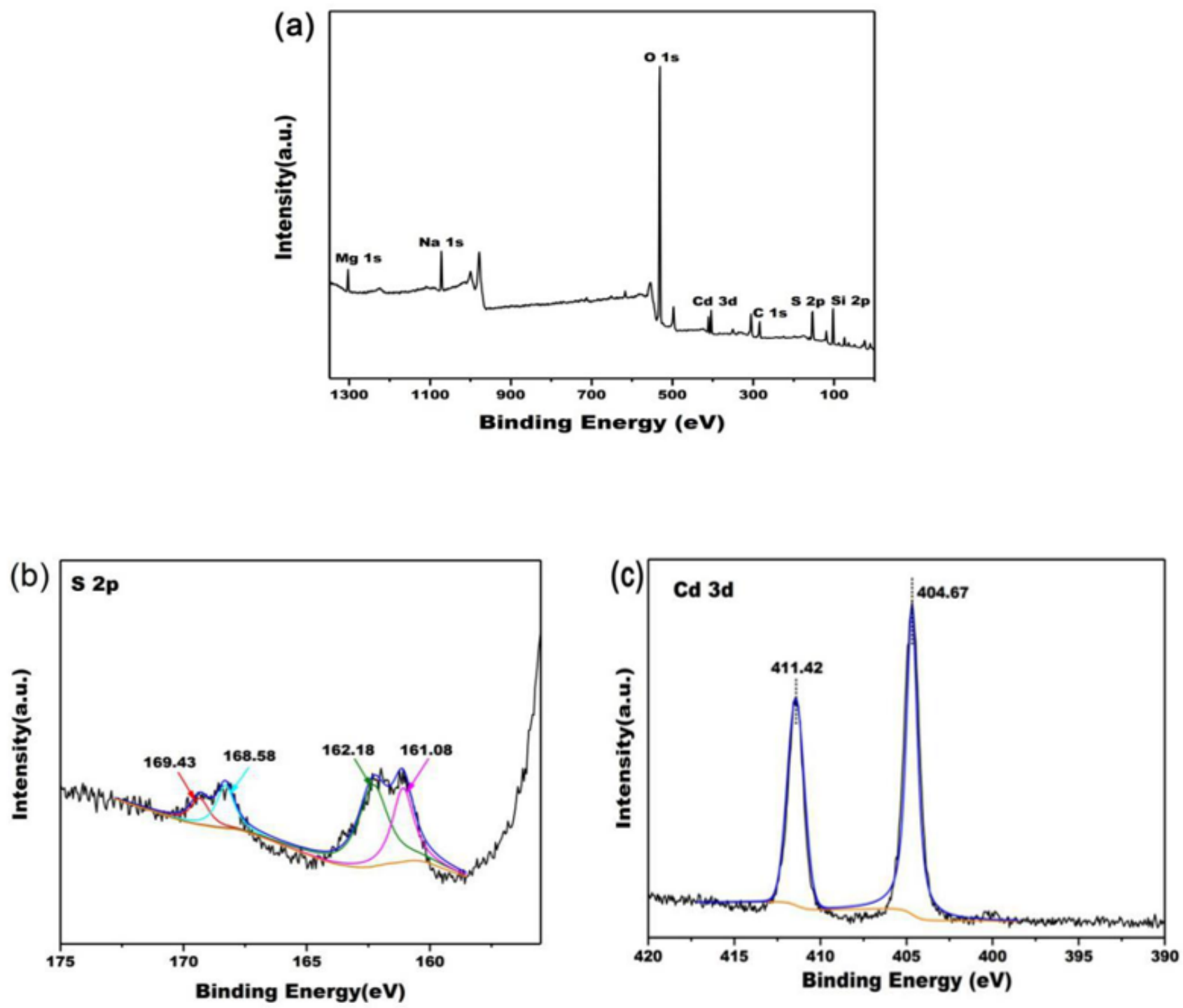

Figure 3

(a) XPS spectrum of montmorillonite loaded with cadmium sulfide; (b) XPS spectrum of S2p scan; (c) XPS spectrum of S2p scan of CdS-M. 

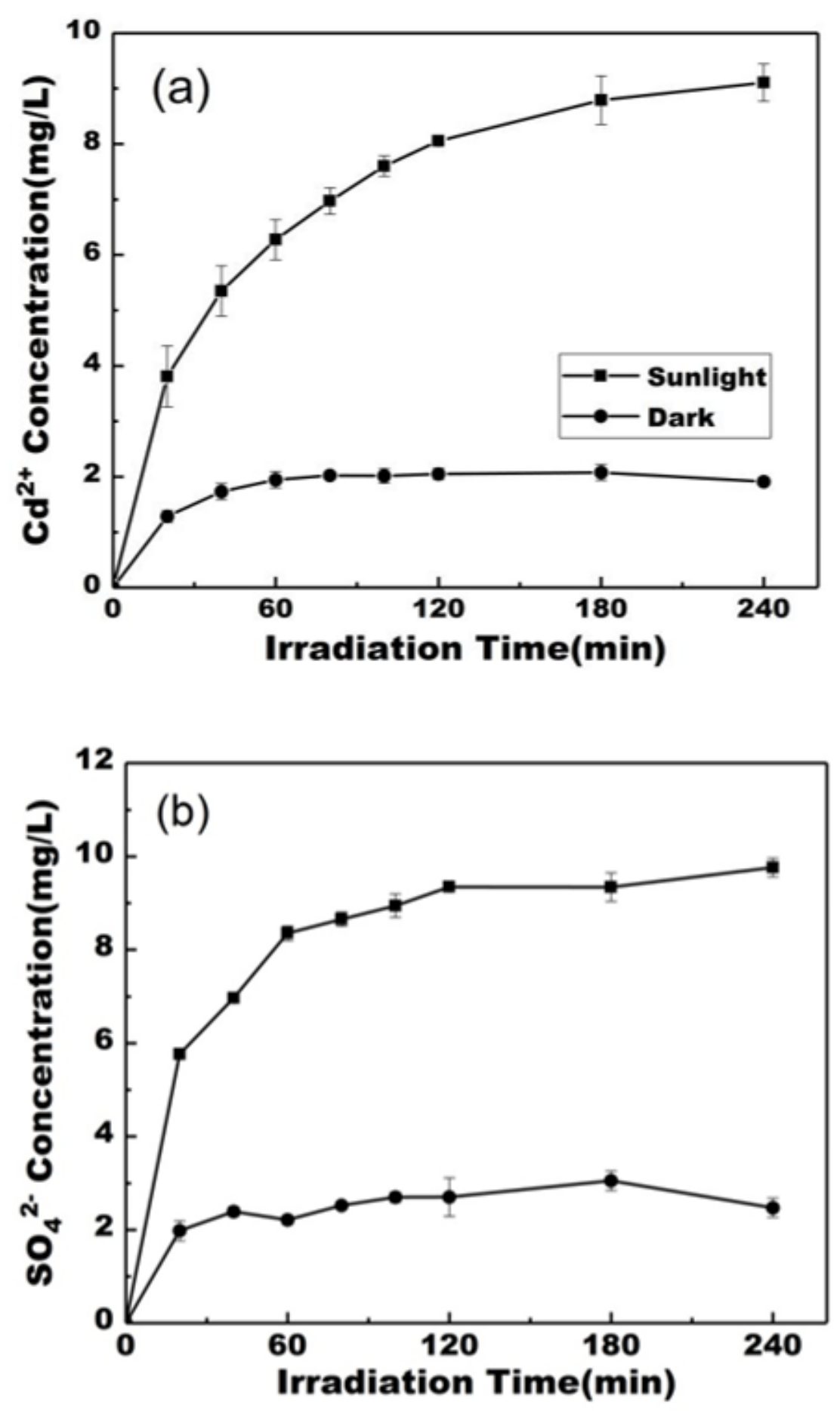

Figure 4

(a) Cd2+ Concentration between sunlight and dark conditions; (b) SO42- Concentration between sunlight and dark conditions. 

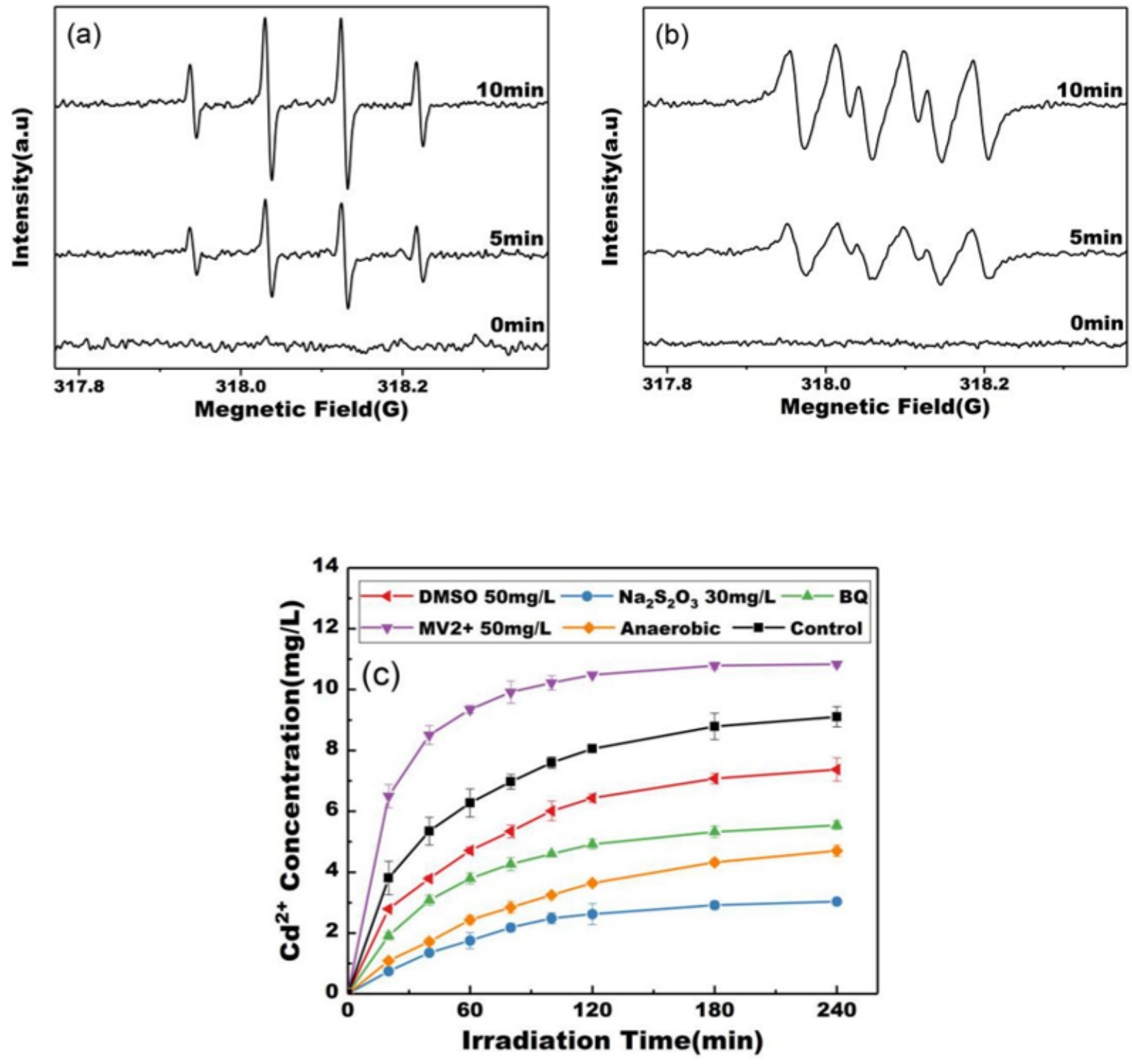

Figure 5

(a) EPR detection results of hydroxyl radical under different light conditions; (b) EPR detection results of superoxide anions under different light conditions; (c) Cd2+ concentration in mechanism exploration experiment. 

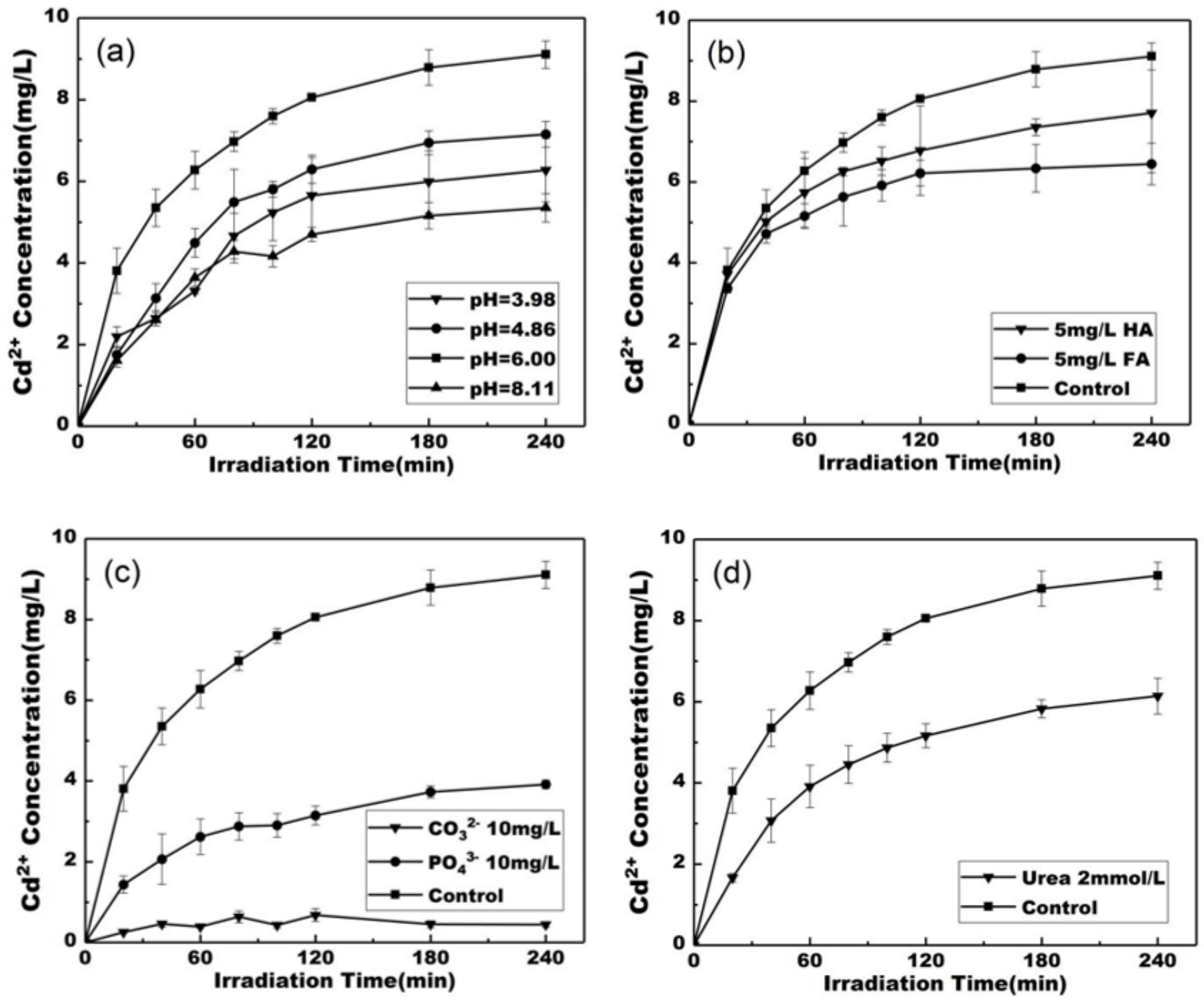

Figure 6

Effects of (a) initial pH; (b) DOM; (c) CO32- and PO43-; (d) urea on release of Cd2+ in the solution. 

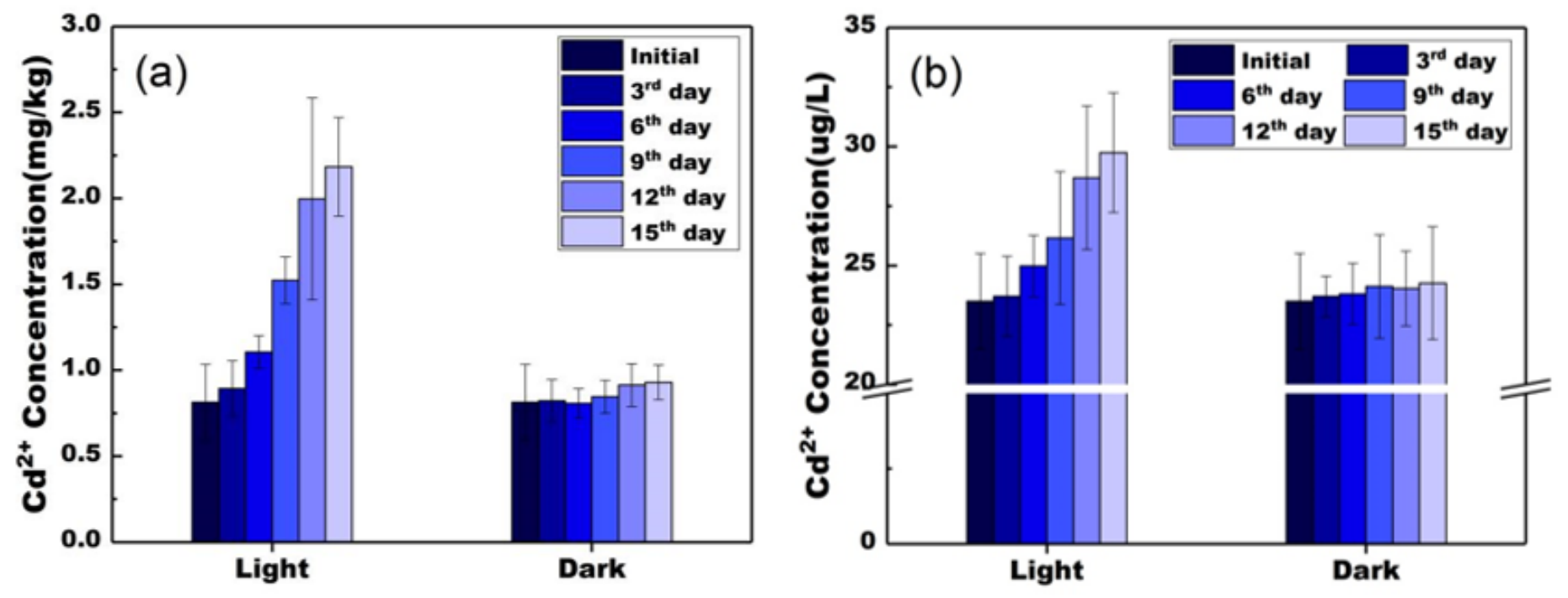

Figure 7

(a) Changes of DTPA-extractable Cd in soil and (b) Cd2+ concentration in suface water.

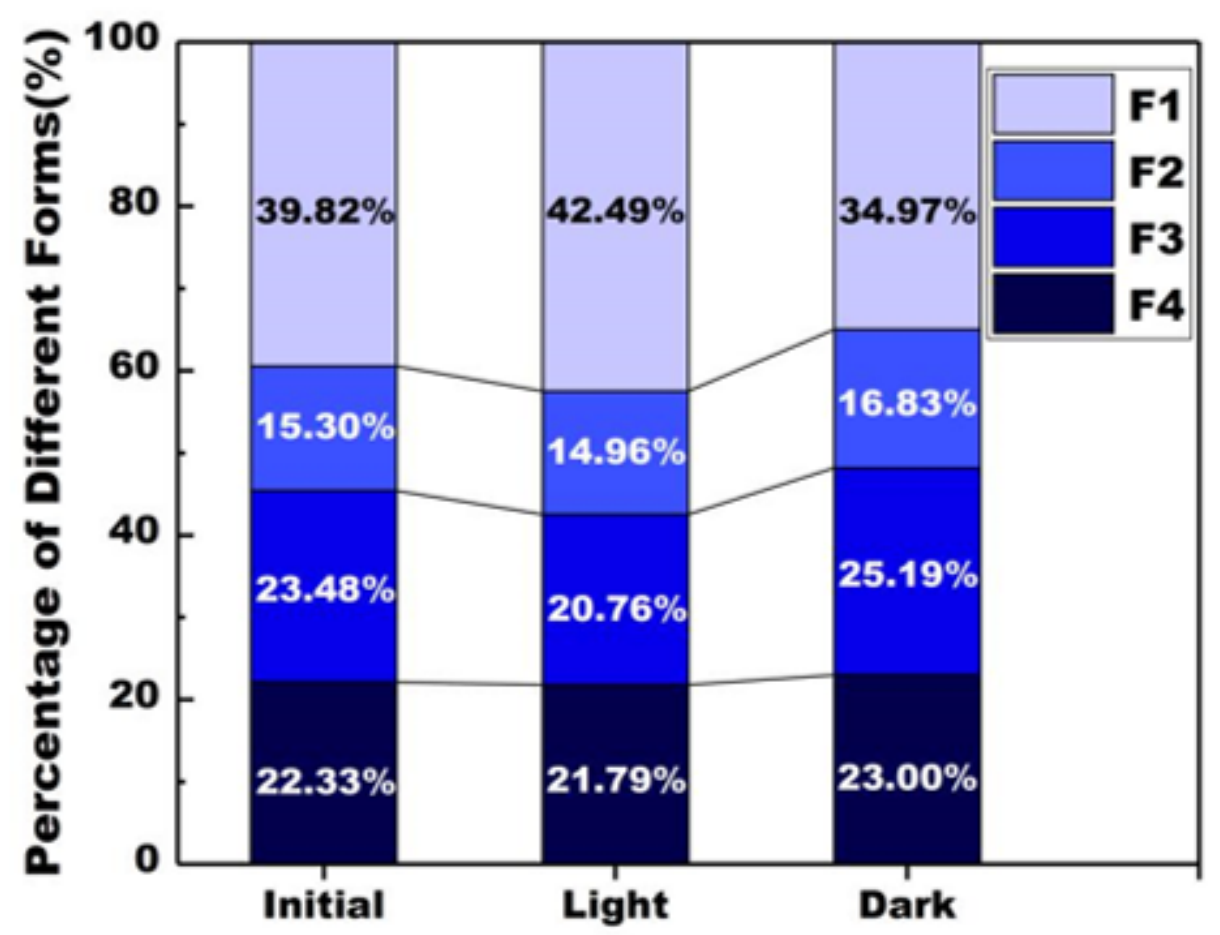

Figure 8

Sequential chemical extraction of $\mathrm{Cd}$ in the initial topsoil and soils after 15 days treatment. (F1: acidextractable, F2: reducible fraction, F3: oxidizable fraction, F4: residual fraction).

\section{Supplementary Files}


This is a list of supplementary files associated with this preprint. Click to download.

- 4SI.docx 